\title{
Inter-Rater Reliability of the California APS Interview for Decisional Abilities (IDA 3.0-CA)
}

Gregory D. Stevens, PhD, MHS ${ }^{1}$, Kelly Sadamitsu, MPH ${ }^{1}$, Theresa Sivers-Teixeira, MSPA, PA$\mathrm{C}^{1}$, Christina Penate, MFT ${ }^{1}$, Jason Karlawish, $\mathrm{MD}^{2}$, Bonnie Olsen, $\mathrm{PhD}^{1}$

'Department of Family Medicine, Keck School of Medicine, University of Southern California; Alhambra, CA.

2University of Pennsylvania, Departments of Medicine, Medical Ethics and Health Policy, and Neurology, Philadelphia, PA.

Address Correspondence and Reprint Requests to:

Theresa Sivers-Teixeira, MSPA, PA-C

Instructor of Clinical Family Medicine

Keck School of Medicine

University of Southern California

1000 South Fremont Ave, Unit \#80

Alhambra, CA 91803

P: 626.457 .6616

F: 626.457 .4090

E: siverste@med.usc.edu

At the time of the study Dr. Stevens was with the Department of Family Medicine, Keck School of Medicine at USC. He is now with the Department of Public Health at California State University Los Angeles.

This white paper was supported by The California APS Decisional Ability Assessment Project (Grant \# 90EJIG0009-01-01).

Disclosures: Jason Karlawish holds a copyright on The Cornell-Penn Interview for Decisional Abilities (IDA 3.0-CA). Cornell University and The University of Pennsylvania @ 2020. 


\section{Introduction}

There are few structured methods to assess an Adult Protective Services (APS) client's decisional abilities, and none have been evaluated for use by APS workers. In 2019, a randomized-controlled trial $(\mathrm{RCT})$ was undertaken among California APS workers to assess the effectiveness of the Interview for Decisional Ability (IDA 3.0-CA), a new tool developed to guide APS workers to assess suspected victims' ability to make decisions about alleged mistreatment. (Abrams et al., 2019). In preparation for the RCT, we determined the inter-rater reliability of the IDA 3.0-CA tool when applied to vignettes of client decisional scenarios. Responses to IDA 3.0CA vignettes were used as the primary outcome measurement in the RCT.

\section{Methods}

\section{Developing Client Vignettes}

Our research team, overseen by a geriatric psychologist, Dr. Bonnie Olsen, geriatric-specialized physician assistant, Theresa Sivers-Teixeira and family therapist, Christina Penate working collaboratively with APS, developed 12 client vignettes that presented hypothetical discussions between APS workers and clients. The vignettes were designed to reflect a variety of risks (physical abuse, sexual abuse, neglect, financial neglect, psychological/mental abuse, and selfneglect) and levels of client decisional ability. Consideration was given to diversity in client gender, race/ethnicity, socioeconomic status, and geography.

Each vignette provided background information on a fictional client and was accompanied by an IDA 3.0-CA form that was completed with quotes from a hypothetical interview between the client and an APS worker.

The vignettes and completed IDA 3.0-CA forms went through several rounds of review by the members of our team, with revisions made to the setting, dialogue and risk factors to assure that they reflected the likely experiences of APS workers.

\section{Pre-Testing Client Vignettes}

Five content experts familiar with development of the IDA tool reviewed the completed IDA 3.0CA forms for each client vignette and provided judgements about whether the client had the ability to (1) Understand, (2) Appreciate, and (3) Reason about a risk presented in the vignette. For each judgement question, there were three response options: yes, maybe and no. These judgements mirrored the three steps of the IDA 3.0-CA tool.

We evaluated the level of agreement between the five experts on each of the judgements. Each of the five experts also provided a rating of the difficulty of the vignette (extremely easy, somewhat easy, neither easy nor difficult, somewhat difficult, extremely difficult) to help us 
determine whether any of the cases were too easy or difficult to be useful. Based on these results, we selected eight vignettes that had adequate agreement among the experts to pilottest the IDA 3.0-CA and evaluate its reliability. The vignettes are provided in Appendix A.

\section{Testing Client Vignettes for Inter-Rater Reliability}

Fifty-four APS personnel from the Southern California region who had been trained to use the IDA 3.0-CA were invited to participate in testing the instrument. They were randomly divided into four groups and asked to review two assigned client vignettes and the accompanying completed IDA 3.0-CA forms, and to make judgements (yes, no, maybe) for the three steps of the IDA 3.0CA (i.e. client's ability to (1) Understand, (2) Appreciate, and (3) Reason about the risk described in the vignette).

\section{Analysis}

We assessed the extent to which IDA 3.0-CA trained APS personnel reached similar conclusions about a client's decisional ability (i.e., inter-rater reliability) when presented with the client vignettes accompanied by a completed IDA 3.0-CA form. For each client scenario, we calculated the percent correct among respondents for each of the three judgements and an overall percent correct score for the vignette.

The inter-rater reliability (Cohen's Kappa) was calculated using Stata 13. A Kappa statistic was calculated for each vignette and for the vignettes overall. Landis and Koch provide guidance on levels of Cohen's Kappa that are considered adequate inter-rater reliability (Landis \& Koch, 1977). Scores of 0.81 to 1.00 indicate near-perfect agreement, 0.61 to 0.80 indicate substantial agreement, and scores of 0.41 to 0.60 indicate moderate agreement. An overall score below 0.41 was considered inadequate reliability for our purposes.

\section{Results}

A total of 39 APS personnel participated in the pilot-study (72\% response rate). Each client vignette was completed by between 7 and 11 APS personnel (i.e. raters). The lowest percent agreement for any single judgement step was $55 \%$ and the highest was $100 \%$. The percent correct for the vignettes overall (a summary of the three steps) ranged from $67 \%$ to $100 \%$, with an average across the eight vignettes of $87 \%$.

The inter-rater reliability for the vignettes ranged from -0.01 to 1.00 . Four of the cases had Kappa statistics that indicate near perfect agreement $(0.81,1.00,1.00$ and 1.00), one had a Kappa statistic indicating moderate agreement (0.57). Three others had Kappa statistics below an acceptable level. The overall Kappa statistic across all vignettes was 0.66 . 
Table 1: Percent correct, by client vignette

\begin{tabular}{|l|l|l|l|l|l|l|}
\hline \multirow{2}{*}{ Group } & \multirow{2}{*}{ Client Vignette } & \multirow{2}{*}{ Raters } & \multicolumn{3}{|c|}{ Percent Correct } \\
\cline { 4 - 7 } & \multirow{2}{*}{1} & Step 1 & Step 2 & Step 3 & Average \\
\hline 1 & Jones & 11 & $100 \%$ & $100 \%$ & $91 \%$ & $97 \%$ \\
\hline 2 & Chen & 11 & $100 \%$ & $55 \%$ & $100 \%$ & $85 \%$ \\
\hline 2 & Liu & 10 & $100 \%$ & $100 \%$ & $100 \%$ & $100 \%$ \\
\hline 3 & Walker & 10 & $100 \%$ & $100 \%$ & $100 \%$ & $100 \%$ \\
\hline 4 & Morgan & 7 & $86 \%$ & $86 \%$ & $100 \%$ & $90 \%$ \\
\hline 4 & Baqri & 7 & $57 \%$ & $57 \%$ & $86 \%$ & $67 \%$ \\
\hline & Perez & 11 & $91 \%$ & $73 \%$ & $64 \%$ & $76 \%$ \\
\hline
\end{tabular}


Table 2: Inter-rater reliability, by client vignette

\begin{tabular}{|l|l|l|l|l|}
\hline Group & Client Vignette & Raters & Kappa & p-value \\
\hline 1 & Jones & 11 & 0.87 & $<\mathbf{0 . 0 0 1}$ \\
\hline 1 & Chen & 11 & 1.00 & $<\mathbf{0 . 0 0 1}$ \\
\hline 2 & Liu & 10 & 1.00 & $<\mathbf{0 . 0 0 1}$ \\
\hline 2 & Walker & 10 & 1.00 & $<\mathbf{0 . 0 0 1}$ \\
\hline 3 & Morgan & 7 & 0.57 & $<\mathbf{0 . 0 0 1}$ \\
\hline 3 & Baqri & 7 & -0.01 & 0.53 \\
\hline 4 & Perez & 11 & 0.25 & $<\mathbf{0 . 0 0 1}$ \\
\hline 4 & Banks & 11 & -0.08 & 0.851 \\
\hline Total & All & $\mathbf{3 9}$ & $\mathbf{0 . 6 6}$ & $<\mathbf{0 . 0 0 1}$ \\
\hline
\end{tabular}

\section{Conclusions}

We observed a high level of agreement (both percent agreement and inter-rater reliability) among APS personnel using the IDA 3.0-CA (as applied to client vignettes). The Kappa statistic of 0.66 for the responses to client scenario vignettes overall suggests a substantial level of reliability. The results suggest that APS personnel using the IDA 3.0-CA have a high likelihood of reaching similar conclusions about a client's decisional ability when provided the same client vignettes.

There are several limitations to the work. First, the client vignettes may not reflect real world settings and performance could be worse or better in the real-world given the ability to ask additional questions, observe contextual clues, body language and hear tone. Second, three of the case vignettes had relatively low agreement. For the purposes of the RCT, we dropped the 
two poorest performing vignettes, resulting in six vignettes used to evaluate the IDA CA-3.0. It appeared that the three vignettes with poor agreement were more complex and caused some confusion for respondents. Third, we grouped judgements of maybe/yes into one category because both of these judgements result in the same administrative action in the IDA (as IDA steps are dependent on each other). Had we applied more strict criteria (requiring judgements of "maybe" to match "maybe" exactly, etc.), the reliability would have declined overall (Kappa = 0.28), and doing so would be inconsistent with the application of the tool in practice.

\section{Acknowledgements}

We would like to thank the following individuals who participated in reviewing the case vignettes as content experts: Robert Abrams, MD, Pamela Ansell, MSW, Renee Carr, Bree Cunningham, David Franklin, PsyD, MHA, Erik Lande, PhD, Veronica LoFaso, MD, Adria Navarro, PhD, LCSW, Stacey Wood, PhD.

We would also like to acknowledge Risa Breckman, LCSW and Mark Lachs, MD for their work on the development of the IDA tool. 


\section{REFERENCES}

Abrams, R. C., Ansell, P., Breckman, R., Karlawish, J., Lachs, M., Holt-Knight, D., Needell, N., Rogers, G., \& LoFaso, V. (2019). The Interview for Decisional Abilities (IDA): a tool to assess the decisional capacity of abused and neglected older adults. Journal of elder abuse \& neglect, 31(3), 244-254.

Landis, J. R., \& Koch, G. G. (1977). The measurement of observer agreement for categorical data. Biometrics, 33(1), 159-174. 


\section{APPENDIX}

\section{Case Scenario Vignettes}

\section{Group 1}

Case \#1: Mr. Jones is an 86-year-old African American man who is recently widowed and lives alone in his own home. His neighbor John goes to bank with the client and withdraws large sums of money totaling $\$ 30,000$ in one month. The bank teller reported to APS and froze the account pending investigation. You've completed part of your investigation, and you're concerned about financial neglect and the client's decisional ability.

Risk: Financial neglect/Using funds without permission

Case \#2: Mrs. Chen is an 86-year-old woman who lives with her son, daughter-in-law and two high school aged grandsons in her son's very large home in the suburbs outside the city. She came to the US 20 years ago after her husband died of cancer. Her son has been in the US since his college years and insisted that his mother come to live with his family after his father passed. Mrs. Chen is small, quite frail and speaks little English. She suffered a stroke several years ago leaving her with right sided weakness. She never leaves the home without family. She is cared for by her daughter-in-law during the week and by hired caregivers on weekends. The caregiving agency weekend staff reported to supervisors that they noted significant bruising on her arms, back and legs. The supervisor then made an APS report. You completed your initial investigation and have concerns about whether the client has been physically assaulted, and you question her decision-making ability.

Risk: Physical abuse - Assault/battery

\section{Group 2}

Case \#1: Ms. Liu is a 92-year-old woman who lives with her daughter and her family in her daughter's home. Ms. Liu is visibly thin and has trouble walking. APS has been called to investigate after a concerned neighbor reported hearing loud crying on a daily basis and was not allowed to see or speak to Ms. Liu. You've completed part of your investigation, and you're concerned about neglect/physical isolation and the client's decisional ability.

Risk: Neglect/Physical isolation

Case \#2: Mrs. Walker is a 69-year-old African American woman who lives in her own home with her 45-year-old daughter. She was divorced many years ago and raised her 3 children on her own. Mrs. Walker worked throughout her life as librarian and has been retired for the past 4 years. Her daughter Wanita has been hospitalized several times this year for depression with suicidal ideation and has not been employed for the past 5 years. Mrs. Walker's oldest son, Teddy, reported to APS his belief that Wanita has been stealing money from his mother. You 
completed your initial investigation and have concerns about whether the client is being financially abused, and you question her decision-making ability.

Risk: Financial neglect/Using funds without permission

\section{Group 3}

Case \#1: Ms. Morgan is a 67-year-old Caucasian woman who has lived in a small home that she has owned for over 40 years. She lives outside of town on a county road with few neighbors. She never married and has no children. She is a retired postal worker. APS was contacted by the local fire department who had been called to her home to put out a small fire, which was out by the time they arrived. The home is filled with the stench of rat droppings and all of the rooms are filled almost floor to ceiling with papers and boxes spilling over with miscellaneous items. There remains only a small path of floor space to get from room to room. Your initial investigation supports the report of self-neglect, and now you are concerned that Ms. Morgan does not have the ability to make decisions about her own needs.

Risk: Self-neglect - Inadequate/dangerous housing

Case \#2: Mr. Baqri is a 73-year-old Pakistani man who has lived in a small downtown apartment alone the last 20 years. He worked as an independent taxi driver for many years after coming to the U.S. He stopped driving and retired 3 years ago after multiple complaints about his driving and inability to find his way around the city. He never married and has no children. His brother continues to visit him on occasion, but he is otherwise on his own with a limited social support. His neighbor called APS to report that on multiple occasions, she had found him in the hallway unable to remember where his apartment was located. Per his past medical records, he has been diagnosed with mild cognitive impairment, but he hasn't been seen by his doctor for almost two years. After your initial investigation, you found there was little food in the house, and Mr. Baqri appeared to be very thin. You are concerned about the client's decisional ability and self-neglect.

Risk: Self-neglect/Inadequate physical care

\section{Group 4}

Case \#1: Ms. Perez is a 77-year-old Spanish-speaking woman with Type 1 diabetes. She lives in an apartment with her 48-year-old son, who works nights to support them. APS has been called to investigate after several ambulance trips to the emergency department for uncontrolled blood sugar in the last 2 months. She was also found on multiple occasions to have a very high blood alcohol level. You've completed part of your investigation, and you're concerned about self-neglect/alcohol abuse and the client's decisional ability.

Risk: Self-neglect/Alcohol abuse 
Case \#2: Mr. Banks is an 82-year-old African American man who lives alone. He is a frail man and needs assistance getting around. At one of his doctor's visits, Mr. Banks reported that his step-daughter handles his finances and transportation needs, but that she was often very mean to him. She tells him that if he doesn't do certain things the way she wants them to be done, she will put him in a nursing home, and he won't get to see his grandchildren. His physician filed a report with APS. You've completed part of your investigation, and you're concerned that the client may be suffering emotional trauma/neglect and are worried about his decisional ability.

Risk: Psychological/Mental - Emotional trauma/neglect 